Article

\title{
Satellite InSAR as a New Tool for the Verification of Landslide Engineering Remedial Works at the Regional Scale: A Case Study in the Three Gorges Resevoir Area, China
}

\author{
Shuhao Liu ${ }^{1}$, Samuele Segoni ${ }^{2}{ }^{\circledR}$, Federico Raspini ${ }^{2}$, Kunlong Yin ${ }^{1, *}$, Chao Zhou ${ }^{3}{ }^{(0)}$, \\ Yiyue Zhang ${ }^{1}$ and Nicola Casagli ${ }^{2}$ (I) \\ 1 Faculty of Engineering, China University of Geosciences, Wuhan 430074, China; liush@cug.edu.cn (S.L.); \\ zyycug@163.com (Y.Z.) \\ 2 Earth Sciences Department, University of Firenze, Via La Pira 4, 50121 Florence, Italy; \\ samuele.segoni@unifi.it (S.S.); federico.raspini@unifi.it (F.R.); nicola.casagli@unifi.it (N.C.) \\ 3 School of Geography and Information Engineering, China University of Geosciences, Wuhan 430078, China; \\ zhouchao@cug.edu.cn \\ * Correspondence: yinkl@cug.edu.cn
}

Received: 22 August 2020; Accepted: 9 September 2020; Published: 16 September 2020

check for updates

\begin{abstract}
Several countries worldwide are funding large-scale programs to mitigate landslide risk by implementing engineering remedial works. However, the overall effectiveness of such measures is rarely monitored, and they are typically performed at the slope scale without fully exploiting the wide-area capabilities of remote sensing technologies. A multi-scale and multi-source monitoring procedure for evaluating the slope stability and the effectiveness of related remedial works was proposed in this study and applied in the middle section of the Three Gorges Reservoir Area (TGRA), China. The area is highly exposed to landslide hazards, and a massive program of engineering remedial works was recently implemented. Satellite interferometric synthetic aperture radar (InSAR)-based techniques were first exploited at the regional scale with the objective to provide a general overview of the deformative scenario and to highlight localized problems (active landslides or high deformation zones) to be further investigated; then, local-scale field investigation and multi-source ground monitoring data were employed to verify the deforming states of active landslides and to evaluate the effectiveness of the landslide engineering remedial works. The results indicated that, among the 310 mapped landslides in the study area, 52 were identified to be active and in a slow-moving state by satellite InSAR; Among the 58 controlled landslides, 9 of them were suspected to be active in a slow-moving state and require further concern. Particular attention was paid to two controlled landslides that were found in a continuously and progressively deforming state. We observed that the regional-scale program of slope stabilization was highly successful; however, the variation of the surrounding environmental setting could have led to landslide reactivation or partial invalidation of the landslide remedial works. The proposed multi-scale and multi-source monitoring framework is low-cost, easy to perform, and very straightforward to communicate to citizens and authorities. It can be easily implemented with very wide areas to assess the slope stability and to investigate the effectiveness of large-scale governmental risk mitigation programs, identifying precursor signals that could allow for intervention before reaching critical conditions.
\end{abstract}

Keywords: landslide; InSAR; the Three Gorges Area; landslide engineering remedial work; monitoring 


\section{Introduction}

Landslides, as the most common natural geohazard type in mountainous areas, often cause heavy economic loss and human casualties [1]. According to the statistical data in the Three Gorges Reservoir Area (TGRA), increasing slope instabilities have occurred since the establishment of the Three Gorges Dam and the official impoundment of the reservoir [2-4]. As a world-famous example of a human engineering project seriously impacting the surrounding environment, the TGRA provides a perfect scenario for scholars around the word [5]. Since the official impoundment in 2003, over fifteen years of reservoir water level fluctuations have influenced the stress forces redistribution in the reservoir banks, thus fostering instability and mass movements [6]. After the initial rise, the amount of geomorphic movements and landslide occurrences declined each year as the reservoir bank stabilized [7]. Huge amounts of human and monetary resources were injected to carry out a large number of investigations and engineering remedial works in the reservoir bank area, aiming at a full understanding of the reservoir bank stability [8].

In recent years, the trend of technical innovation and method improvements intensified due to the gradual maturity of advanced technologies, such as ground-based interferometric synthetic aperture radar (InSAR) [9], InSAR [10], and light detection and ranging (LiDAR) [11]. Currently, InSAR has been accepted and widely used in many landslide investigations. Undoubtedly, InSAR is an effective and powerful tool in hazard researches; however, it is still inadequate to study the intricate relationship between deformation and failure simply according to InSAR ground surface deformation analysis results. At present, the applications of InSAR in the geohazard field can be divided into six categories: Hazard identification [12,13], hazard mapping [14], systematic monitoring (e.g., [15,16]), prediction and early warning [17], and stability analysis [18] and hazard remedial measures effect inspection [19,20].

As the earliest experimental site of landslide InSAR monitoring technology, under the support of the China Geological Survey, corner reflectors were established on the Xintan landslide and Lianziya landslide in the TGRA early from 1999 [21]. For over ten years of technical advancement, more monitoring test sites were set up in representative landslides, such as Shuping landslide and Fanjiaping landslide, etc. hoping to find a reliable InSAR monitoring technique process [3,22,23].

Due to its unique geographic position and geological conditions, large-scale engineering remedial work was conducted in the TGRA. Landslides with engineering remedial work were typically considered to be stable and no longer monitored, which led to an underestimation of the residual risk. Research monitoring the performance of the remedial work also focused on single landslides instead of the large scale of engineering prevention work covering a regional space $[19,20]$. To quantitively evaluate the performance of remedial work, researchers carefully selected the evaluation indexes and divided them into five categories according to the fundamental types and hazard prevention features, to build an evaluation index system [24].

The objective of this work was to study the geohazards, with a special focus on controlled landslides. In particular, the activity relied on the following steps: (i) Large-scale slow-moving landslide mapping to identify the active landslides, employing InSAR-HCA (hotspot and clustering analysis); (ii) single slope-scale landslide deformation analysis combining InSAR time-series analysis, conventional ground monitoring, and field investigation methods; and (iii) landslide engineering remedial work performance evaluation considering its operating conditions and landslide deformation.

\section{Materials and Methods}

\subsection{Geological and Geomorphological Settings}

The TGRA is a typical narrow strip reservoir with an average width of $1.576 \mathrm{~m}$. When the water level of the TGRA reaches its normal water level of $175 \mathrm{~m}$, the total length of the reservoir is $663 \mathrm{~km}$. The study area is located in the central reaches of the TGRA, Southwestern China, within longitude $108^{\circ} 18^{\prime}-108^{\circ} 48^{\prime}$ east and latitude $30^{\circ} 43^{\prime}-31^{\circ}$ north (Figure 1). This area belongs to Chongqing, and the total area is approximately $1350 \mathrm{~km}^{2}$. The region is surrounded by mountains with elevations ranging 
from 45 to $1598 \mathrm{~m}$ above sea level, with the Yangtze River flowing across from south to northeast. Several tributaries flow in the main river, shaping a well-developed water system. The average annual rainfall reaches $1200-1400 \mathrm{~mm}$, and the monsoon season is from April to September, when the maximum monthly rainfall is larger than $300 \mathrm{~mm}$.

(a)

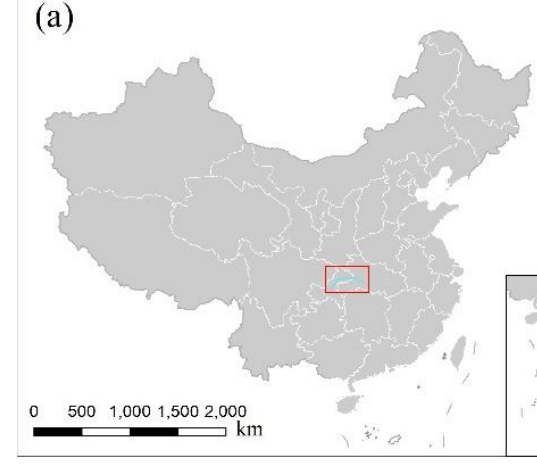

(b)

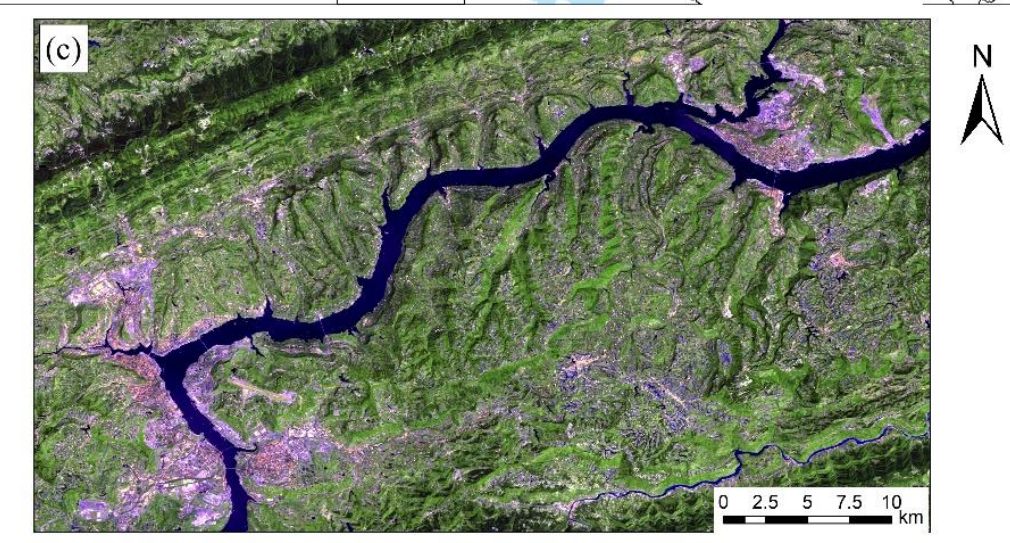

Figure 1. (a) Site map of the Three Gorges Reservoir Area (TGRA) in China. (b) Location of the study area in the TGRA. (c) A false color synthetic image showing the geographic coverage of the study area.

In Figure 1, a false color synthetic image was generated using bands 8, 4, and 3 of a Sentinel-2 image (acquired on 4 August 2018), to better display the distribution of urban center areas and anthropic elements at risk, with purple indicating the main city constructions and green representing mountainous and vegetated areas.

From a geological point of view, the study area consists of a Mesozoic terrigenous sequence interbedded with Jurassic and Triassic claystone, marlstone, and sandstone, deposited in a nearly horizontal direction (Figure 2). Table 1 provides explanations to the lithological and stratigraphic unit.

The overall topography shows a trend of elevation decline from southeast to northwest. Due to the TGRA regional crustal uplift and the local interbedded strata differential weathering, coupled with the incision effect of the Yangtze river and its tributaries, the overall landscape of this region presents a typical step-like morphology, with eroded multi-level fluvial terraces, floodplains, denuded low mountains, and sporadically distributed hills. The area is affected by tectonism, with developed fold structures characterized by tight anticlines and wide synclinals distributed in echelon form. As the Yangtze river runs right through the core of the main sysclinorium, which consists of the Wanxian syncline, Huangbaixi syncline, and Xinchang anticline, both sides of the riverbank have bedding slopes. Such relation between the slope aspect and strata inclination caused the slope bank structure to be more prone to landslides. Indeed, several studies highlighted that landslides are one of the most important geomorphological processes shaping the landscape of the study area $[25,26]$. 


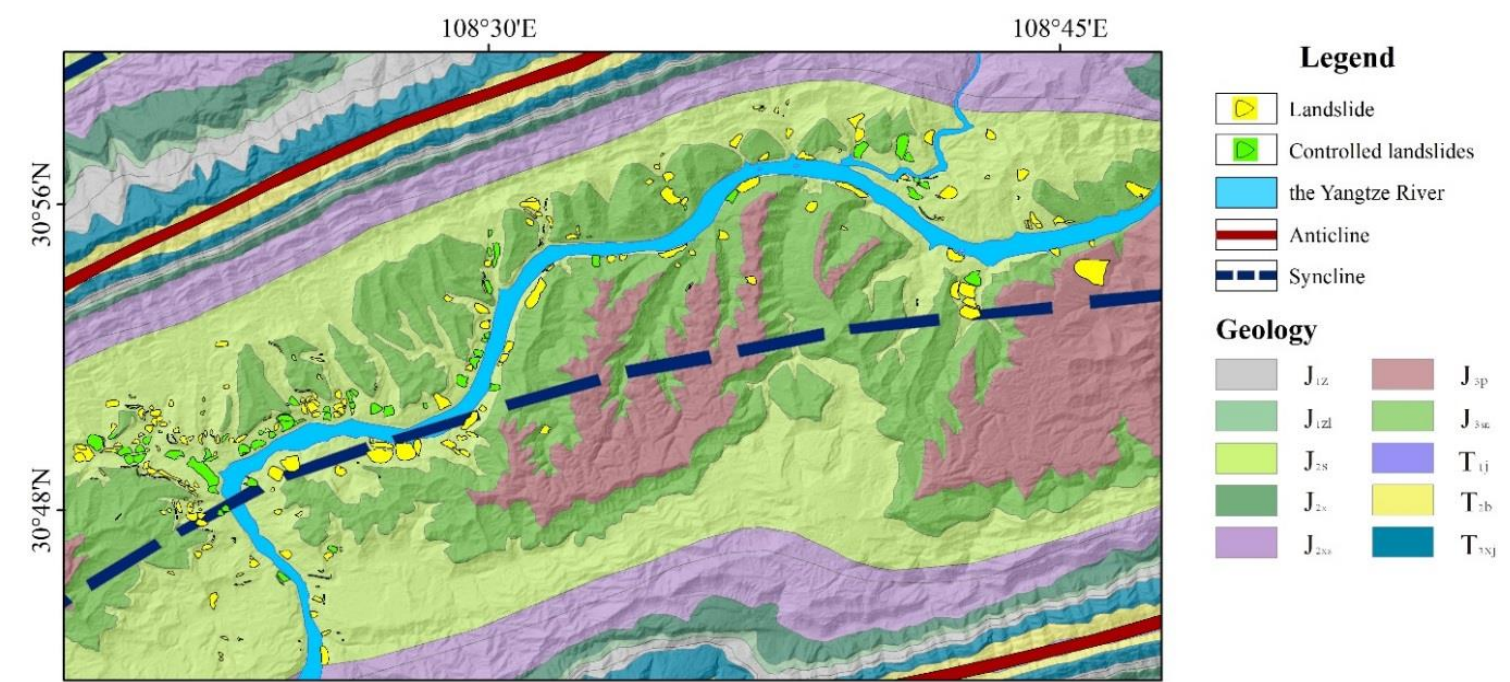

Figure 2. Tectonics and geology of the study area. (see Table 1 for explanations of geological units).

Table 1. Lithology and stratigraphic unit in the study area.

\begin{tabular}{|c|c|c|c|}
\hline Stratum & Stratigraphic Unit & Group & Main Lithology \\
\hline $\mathrm{J}_{1 \mathrm{z}}$ & Lower Jurassic strata & Zhengzhuchong & $\begin{array}{l}\text { Gray quartz sandstone with } \\
\text { interbedded shale }\end{array}$ \\
\hline $\mathrm{J}_{1 \mathrm{zl}}$ & Lower Jurassic strata & Ziliujin & $\begin{array}{c}\text { Shale sandwiching quartz sandstone } \\
\text { and limestone }\end{array}$ \\
\hline $\mathrm{J}_{2 \mathrm{~s}}$ & Middle Jurassic strata & Shaximiao & $\begin{array}{l}\text { Alterative layers of purple red mudstone } \\
\text { and feldspar sandstone or siltstone }\end{array}$ \\
\hline $\mathrm{J}_{2 \mathrm{x}}$ & Middle Jurassic strata & Xintiangou & $\begin{array}{l}\text { Gray yellow feldspar sandstone with } \\
\text { interbedded mudstone }\end{array}$ \\
\hline $\mathrm{J}_{2 \times s}$ & Middle Jurassic strata & Xiashaximiao & $\begin{array}{l}\text { Gray purple feldspar sandstone with } \\
\text { interbedded mudstone }\end{array}$ \\
\hline $\mathrm{J}_{3 \mathrm{p}}$ & Upper Jurassic strata & Penglai & $\begin{array}{l}\text { Gray white quartz sandstone with } \\
\text { interbedded shale }\end{array}$ \\
\hline $\mathrm{J}_{3 \mathrm{sn}}$ & Upper Jurassic strata & Suining & $\begin{array}{l}\text { Red purple quartz sandstone with } \\
\text { interbedded mudstone }\end{array}$ \\
\hline $\mathrm{T}_{1 \mathrm{j}}$ & Lower Triassic strata & Jialingjiang & $\begin{array}{c}\text { Limestone and dolomite, karst breccia, and } \\
\text { dolomite limestone }\end{array}$ \\
\hline $\mathrm{T}_{2 \mathrm{~b}}$ & Middle Triassic strata & Badong & Limestone and sandy mudstone \\
\hline $\mathrm{T}_{3 \mathrm{xj}}$ & Upper Triassic strata & Xujiahe & Light gray lithic sandstone and silty shale \\
\hline
\end{tabular}

\subsection{Landslide Inventory and Landslide Characteristics}

Landslide inventory is the basis for all hazard analyses. The original landslide database was realized by the China Geological Survey, through a series of field investigations and historical landslide data, and later updated by remote sensing, using high-resolution images of Pleiades-1 (22/09/2014) and GF-2(06/12/2015). As landslides within the range of the reservoir area are the main objective of this study, landslides situated far from the riverbank were intentionally excluded from the inventory. The final inventory counted 310 landslides delineated as polygons, including 58 landslides under the control of engineering remedial works and about 30 landslides of interest in ongoing monitoring programs. All the selected landslides can be defined as rotational/translational slides or as complex landslides, with sizes ranging from $1360 \mathrm{~m}^{2}$ to $1.28 \times 10^{6} \mathrm{~m}^{2}$. The information about the landslide boundaries and engineering projects was collected from the third phase of the Three Gorges engineering project geological disasters prevention and control plan, and the related engineering geological survey and design data was based on the work of the Institute of geological environment monitoring, China Geological Survey. 
Statistical analysis of the inventory data demonstrated a strong correlation with the geological setting, with landslides basically occurring in strata with dip angles below $15^{\circ}[26,27]$. In the Sichuan basin, China, such landslides with near horizontal sliding surfaces, represented by landslides in the Wanzhou district, mainly occurred in the Mesozoic sandstone and mudstone strata. Through the analysis of the weak interlayers and age tests in landslide soil masses, the weak layers rich in hydro-expansible montmorillonite were considered as one of the strongest controlling factors of ancient near horizontal slip surface landslides in the Wanzhou district [28].

\subsection{InSAR Dataset and Processing}

To assess the general stability of the test site, the specific characteristics of localized instability areas and the effectiveness of recently implemented remedial works, we set up a multiscale and multi-level procedure combining different monitoring methodologies (Figure 3).

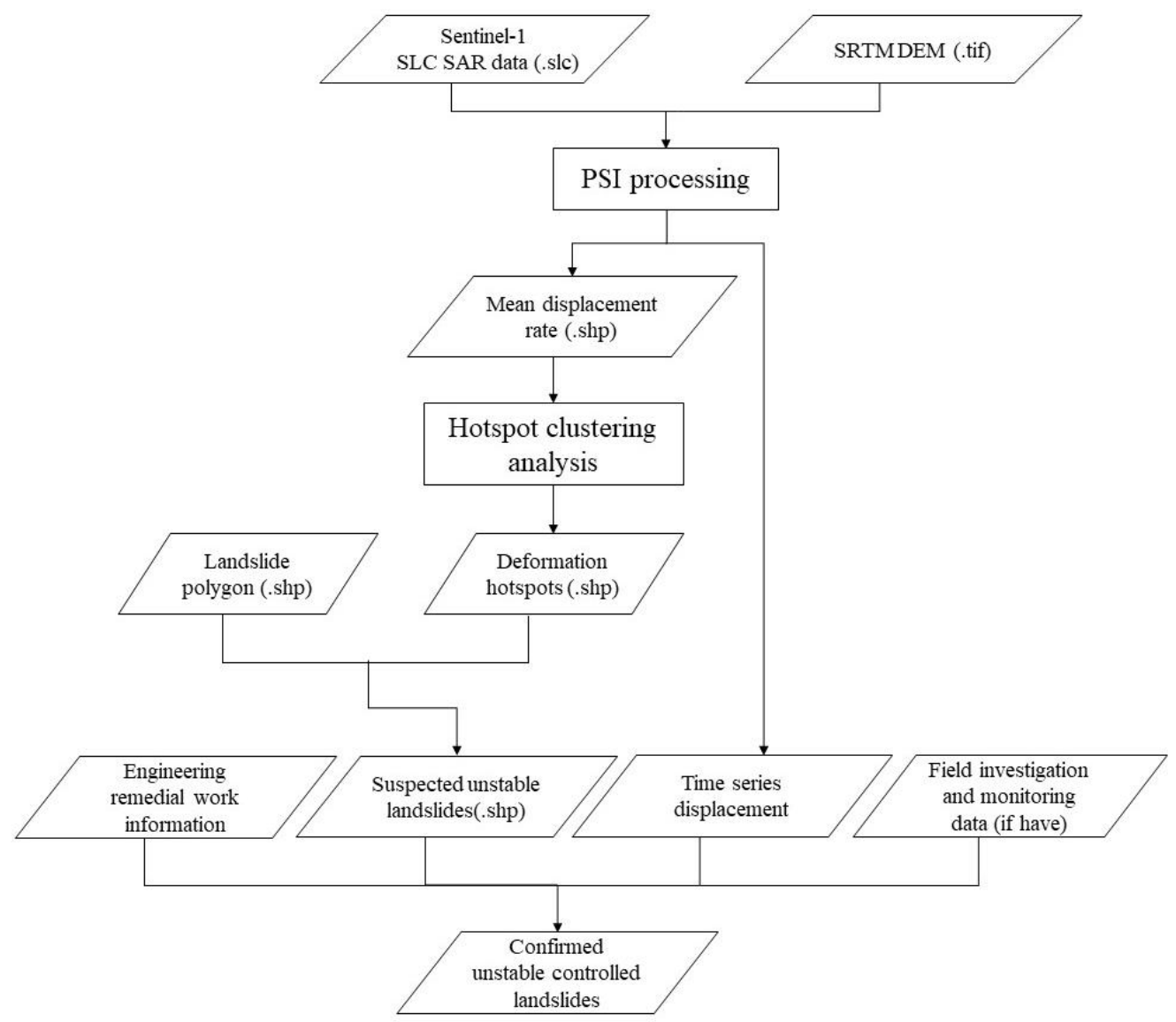

Figure 3. Flow chart illustrating the adopted methodology.

As a leading active remote sensing technique, InSAR techniques were proven to be an effective tool in long-term and slow deformation monitoring [29]. In this study, after the InSAR deformation velocity map was obtained, a statistical method (hotspot analysis) was employed to extract the hotspot from the sparsely distributed PSs, which can exclude the redundant information and indicate deformation concentrated area. Then, according to the landslides inventory data, the landslide edges were delineated as polygons and overlaid on the ground displacement rate map to target the suspected active landslides. For controlled landslides showing deformation trends, analysis of ground-based monitoring data and field investigations were conducted to verify the overall effect of the engineering remedial works.

Equipped with a C-band synthetic aperture radar, Sentinel-1 provides continuous images in various weather conditions at an almost global coverage scale. To obtain the ground deformation 
velocity map for the study area, 70 Sentinel-1 images covering a time span between June 2015 and June 2018 were collected and selected for PSInSAR analyses. More than 980,000 PSs with coherence level above 0.60 were obtained, thus ensuring a sufficient spatial coverage and reliable information about the deformation characteristics (Figure 4). The SRTM (Shuttle Radar Topography Mission) DEM (Digital Elevation Model) covering the study area was used in the generation of differential interferograms and the processing procedure employed the PSInSAR technique [30,31]. First, the precision track parameters file and the DEM of the study area were used for image cropping and registration. Then, the differential interference process was conducted by SARscape 5.2.1 at ENVI 5.3 environment. Finally, the obtained LOS InSAR ground displacement rate was projected at the steepest slope direction to better retrieve the ground deformation trend.

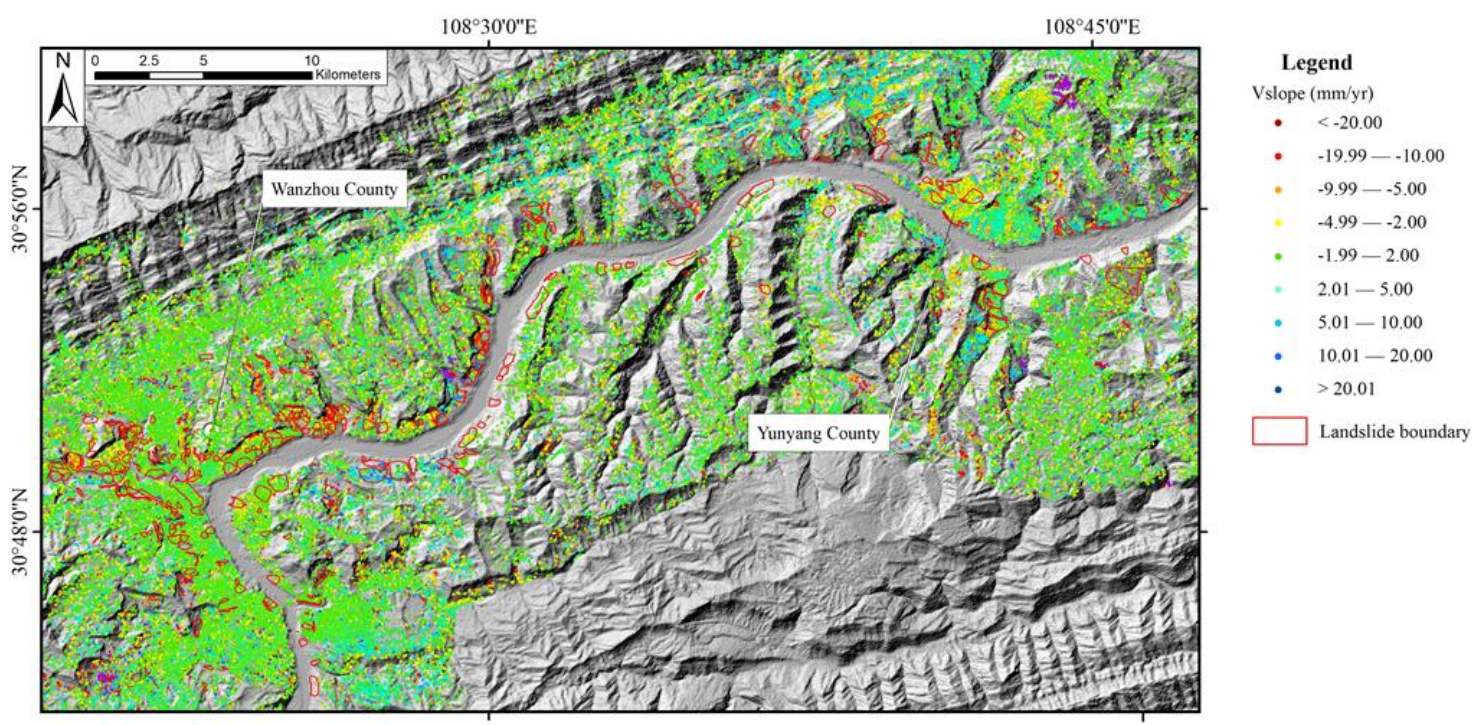

Figure 4. Displacement velocity (Vslope) map of the area generated from the Sentinel-1 data stack.

The above mentioned InSAR analysis process was relatively easy, flexible, and accessible, with totally free satellite radar images and a short machine processing time. Such a method is a reasonable basis for the following regional ground surface stability analysis.

\subsection{InSAR Hotspot Clustering Analysis}

Typically, a cluster of PSs representing relative high deformation velocities tends to aggregate in unstable areas, which are often recognized as active landslides or ground subsidence areas. However, point-based deformation rate maps are scattered and noise-affected, especially in mountainous areas where coherence varies largely in space. Such results can hardly provide reliable information indicating the spatial difference of landslide local deformation [32]. Thus, only point-based PSs with the absolute displacement velocity value above a basic threshold ( $>10 \mathrm{~mm} / \mathrm{yr}$ in this study) and showing obvious spatial aggregation can be used to discern active deformation areas from stable regions.

In this study, we employed the hotspot and clustering analysis (HCA), which uses a statistics approaches, namely Getis-Ord Gis* statistics [33], to identify the hot and cold spots of point clustering. The obtained Z scores measured the extent of the clustering, and the Gi-Bin value identified the hot and cold spots of statistical significance with different levels of confidence intervals. PSs with Z-scores over 2.9 were extracted as 'hotspots' and used to identify mass ground movements, which corresponded to an approximate $99 \%$ confidence interval. Represented by the Gi-Bin values, positive values were rendered with blue and negative values with red. Both colors indicate the location of relevant clustering of PSs, with deeper colors standing for a higher clustering status. The clustering of elements with no statistical significance were rendered with light yellow, which means they provide no reliable information in identifying active landslides or ground deformation. The result is shown in Figure 5a. 


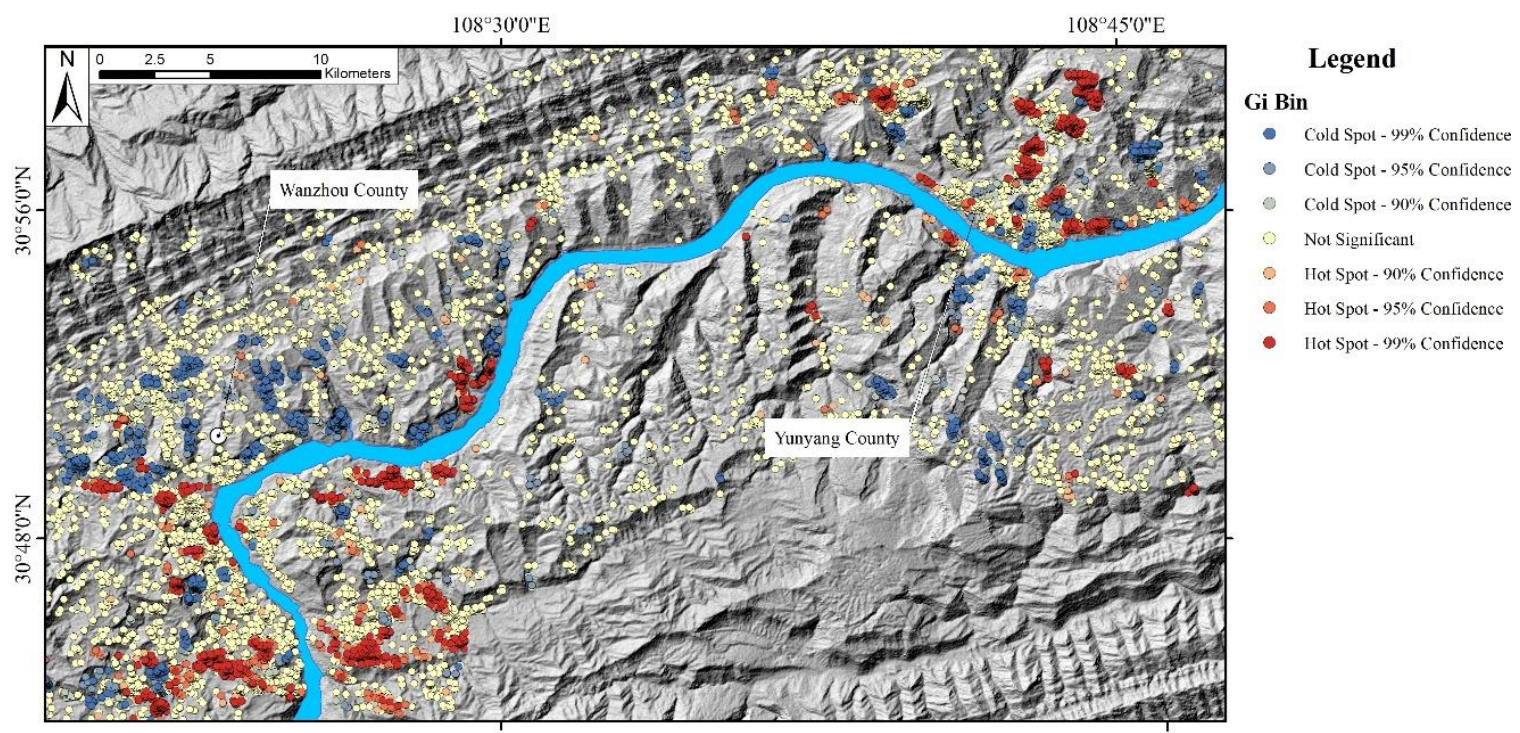

(a)

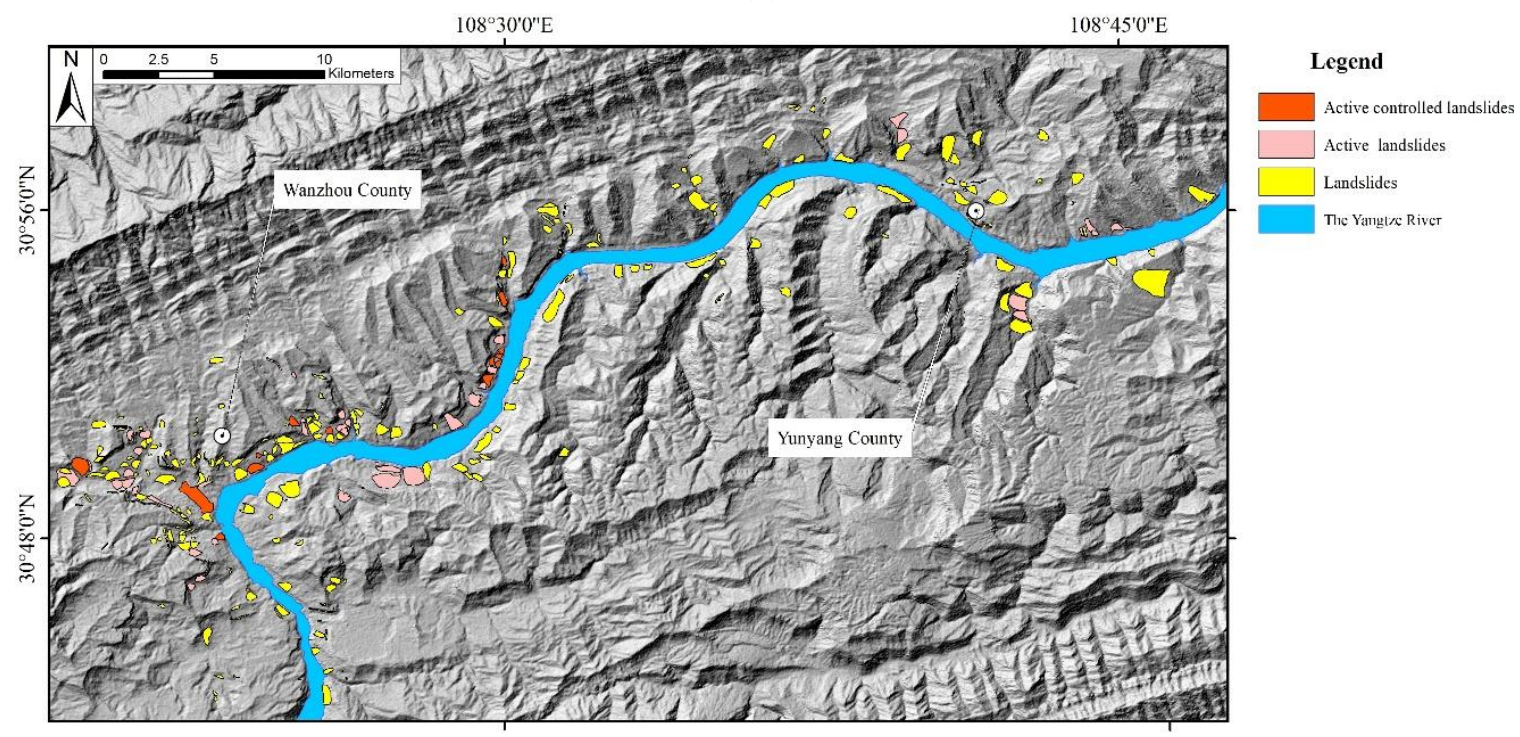

(b)

Figure 5. (a) Persistent Scatterer Interferometry (PSI) hotspot maps of the entire study area including the main district from Wanzhou to Yunyang county. Red hotspots and blue hotspots correspond to the clustering of PSs with high deformation rates. (b) Landslide polygons rendered with different colors according to the hotspot map. Orange: Active landslides with engineering remedial works. pink: Active landslide area without engineering remedial works. Yellow: Other inactive landslides. Four numbered landslides are representative landslides combining field investigation and ground monitoring data, which will be discussed in the following section.

Hotspots, PSs, and landslide polygons can be overlaid on high-resolution Google Earth images in a GIS system to obtain substantial information regarding the exact deformation area, which, in turn, can provide exact targets for further field investigation. Landslide polygons with hotspots insides its boundaries were considered as suspected active landslides, and then a second confirmation step was conducted at the slope scale to verify the effectiveness of the engineering remedial measures for controlled landslides. Different colors were rendered on landslides polygons representing their active level, orange representing active controlled landslides, pink for active uncontrolled landslide and yellow for the remaining inactive landslides (Figure $5 b$ ). 


\subsection{Effectiveness Evaluation of Landslides Engineering Remedial Measures}

Thus, the framework proposed in this study encompasses an evaluation of the effectiveness of remedial works in two steps. The first step uses regional scale satellite monitoring data with the objective to provide a general overview of the regional scale remedial programs and to highlight localized problems to be further investigated. The second step involves local scale evaluations on ground-based landslide monitoring data (if available) and field investigations.

Based on previous InSAR-HCA results, controlled landslides with noticeable ground surface deformations were targeted and received detailed field investigations. The integrity of their major engineering remedial structures, such as anti-slide piles or drainage ditches, were carefully inspected. Other deformation features of these controlled landslides were also closely recorded periodically in case of sudden deforming acceleration, which may cause engineering structure malfunction. Apart from this, other sources of monitoring data, like long-term GPS and borehole inclinometer data, were combined to predict the future deformation trend and the overall stability of landslide.

\section{Results}

\subsection{InSAR Regional Deformation Rate Result and Landslide Hotspot Map}

The displacement rate map in the slope direction over the TGRA from Wanzhou County to Yunyang County is shown in Figure 4. Approximately $93 \%$ of the PSs show displacement rates within $10 \mathrm{~mm} / \mathrm{yr}$ to $-10 \mathrm{~mm} / \mathrm{yr}$, which indicates an overall stable environment of the study region.

The output of PSI-HCA is shown in Figure $5 a$, all the remaining spots have displacement rates at a slope direction over $10 \mathrm{~mm} / \mathrm{yr}$. (>10 mm/yr. or $<-10 \mathrm{~mm} / \mathrm{yr}$ ).

In general, a total of 310 landslides in this region covered an area of $32.16 \mathrm{~km}^{2}$. Engineering remedial works were already performed for 58 landslides. According to the first step (PSI-HCA), 52 out of 310 landslides remain in an active status, which accounts for nearly one sixth all landslides, and a total of 11 controlled landslides were diagnosed as suspected unstable landslides.

Table 2 shows the results of our entire procedure. After combining the field investigation and ground monitoring data, two of the suspected active controlled landslides were confirmed to be active with some obvious deformation features that are continuously developing. The other nine showed different levels of surface deformation, but generally were not as strong as the former two landslides. Continuous attention should be kept on these nine suspected active landslides and periodic field investigations or even ground monitoring instruments are highly recommended depending on the trend of their development. The field investigation and engineering remedial work validation process are presented in following sections. For the 58 landslides under engineering remedial works in this area, $47(81.0 \%)$ were inactive, which corresponds to $82.0 \%$ of the controlled landslides area.

Table 2. Result of the deformation inspection based on the proposed procedure.

\begin{tabular}{ccccc}
\hline & Number & Percentage & Area $\mathbf{( k m}^{\mathbf{2}} \mathbf{)}$ & Percentage of Area \\
\hline Controlled landslides confirmed active & 2 & 0.65 & 0.09 & 0.28 \\
Controlled landslides suspected to be active & 9 & 2.90 & 1.83 & 5.69 \\
Controlled landslides that are inactive & 47 & 15.16 & 8.76 & 27.24 \\
Uncontrolled landslides that are active & 41 & 13.23 & 3.71 & 11.53 \\
Uncontrolled landslide that are inactive & 211 & 68.06 & 17.77 & 55.26 \\
All landslides & 310 & 100 & 32.16 & 100 \\
\hline
\end{tabular}

\subsection{Suspected Active Controlled Landslides}

Table 3 shows the suspected active landslides with engineering remedial work, their highest InSAR displacement rate at the slope direction, the deformation scale, and implemented type of engineering remedial works. The next step of the proposed methodology aimed at identifying potentially instable slopes or the failure of engineering remedial work and confirmed the activity level of this suspected 
cases. Through our field investigations, nine of them (No.1 and No.4-No.11) were considered as very slow deforming, and no signs of persistent deformation were detected on the landslide body or buildings on it. In addition, their engineering remedial structures were all intact and well-functioning, despite that some of them were deeply planted into the ground and hard to check.

Table 3. The maximum slope displacement velocity of controlled landslides acquired by PSInSAR (PSI interferometric synthetic aperture radar) time-series analysis.

\begin{tabular}{|c|c|c|c|c|c|}
\hline No. & Landslide Name & $\begin{array}{c}\text { Max Vslope } \\
(\mathrm{mm} / \mathrm{yr})\end{array}$ & Sliding & $\begin{array}{l}\text { Situation of } \\
\text { Monitoring }\end{array}$ & $\begin{array}{c}\text { Engineering } \\
\text { Remedial } \\
\text { Work }\end{array}$ \\
\hline 1 & Ertunping landslide & 17.29 & Local & InSAR & $1,2,3$ \\
\hline 2 & Dazhou landslide & 15.80 & Local & Ground/InSAR & 1,2 \\
\hline 3 & Kangjiapuo landslide & 17.88 & Local & InSAR & 1,2 \\
\hline 4 & Dadiping landslide & 28.71 & Local & InSAR & 1,2 \\
\hline 5 & Xiaoshipan rockfall & 35.00 & Local & InSAR & $1,2,3$ \\
\hline 6 & Yuanjiadeng landslide & 15.84 & Local & InSAR & 1,2 \\
\hline 7 & Qingcaobei landslide & 19.60 & Local & InSAR & 1,2 \\
\hline 8 & Hufuqiao landslide & 24.13 & Local & InSAR & 1,2 \\
\hline 9 & Sangshuerzu landslide & 12.16 & Local & InSAR & 1,2 \\
\hline 10 & Sharentian landslide & 22.66 & Local & Ground/InSAR & $1,2,3$ \\
\hline 11 & Heping Square landslide & 19.33 & Local & Ground/InSAR & $1,2,3,4$ \\
\hline
\end{tabular}

In this table, engineering remedial work was classified as: 1 . Drainage; 2 . Retaining structures; 3 . Internal slope reinforcement; and 4. Modification of slope geometry [34].

Figure 6 shows the displacement rate map and deformation features of the Ertunping landslide, such as building cracks at the middle part of the sliding body, and bank collapse at the front edge. The landslide showed no obvious signs of continuous overall deformation, and deformation features, such as pre-existing building cracks, also showed no developing tendency. The implemented engineering structures, including anchors on the trailing, anti-slide piles, and retaining wall on the front edge, all maintained fixed positions and functioned well.
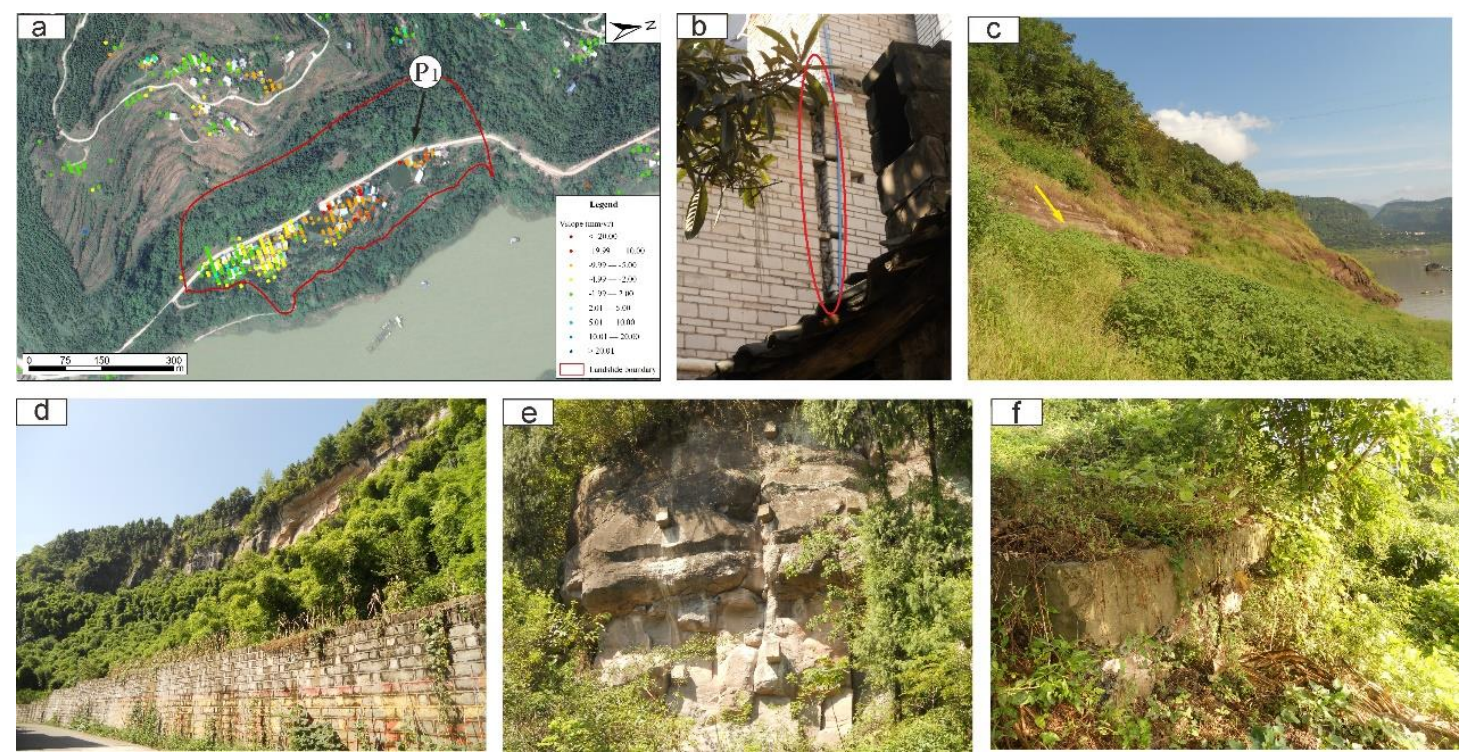

Figure 6. (a) PSInSAR deformation rate map of the Ertunping landslide. (b) Crack observed in a nearby house at site P1. (c) Shear crack at the front edge of the Ertunping landslide. (d) Retaining wall at the landslide front edge. (e) Anchors at the landslide trailing edge. (f) Anti-slide piles at the landslide front edge. 
The Dadiping landslide lies on the bank of a tributary of the Yangtze River. Many risk elements exist on the landslide body, including an elevated highway and many buildings, which significantly increases the load on the Dadiping landslide. Both the InSAR displacement rate map and time-series of local PSs showed an obvious local deformation trend (Figure 7). As the engineering remedial work of Dadiping landslides was designed and implemented in 2016 (which is quite recently), no sign of damage was detected on its engineering structures, which mainly consist of two rows of anti-slide piles, located in the front edge of the landslide, and with the trail edge on one side of the highway, respectively.

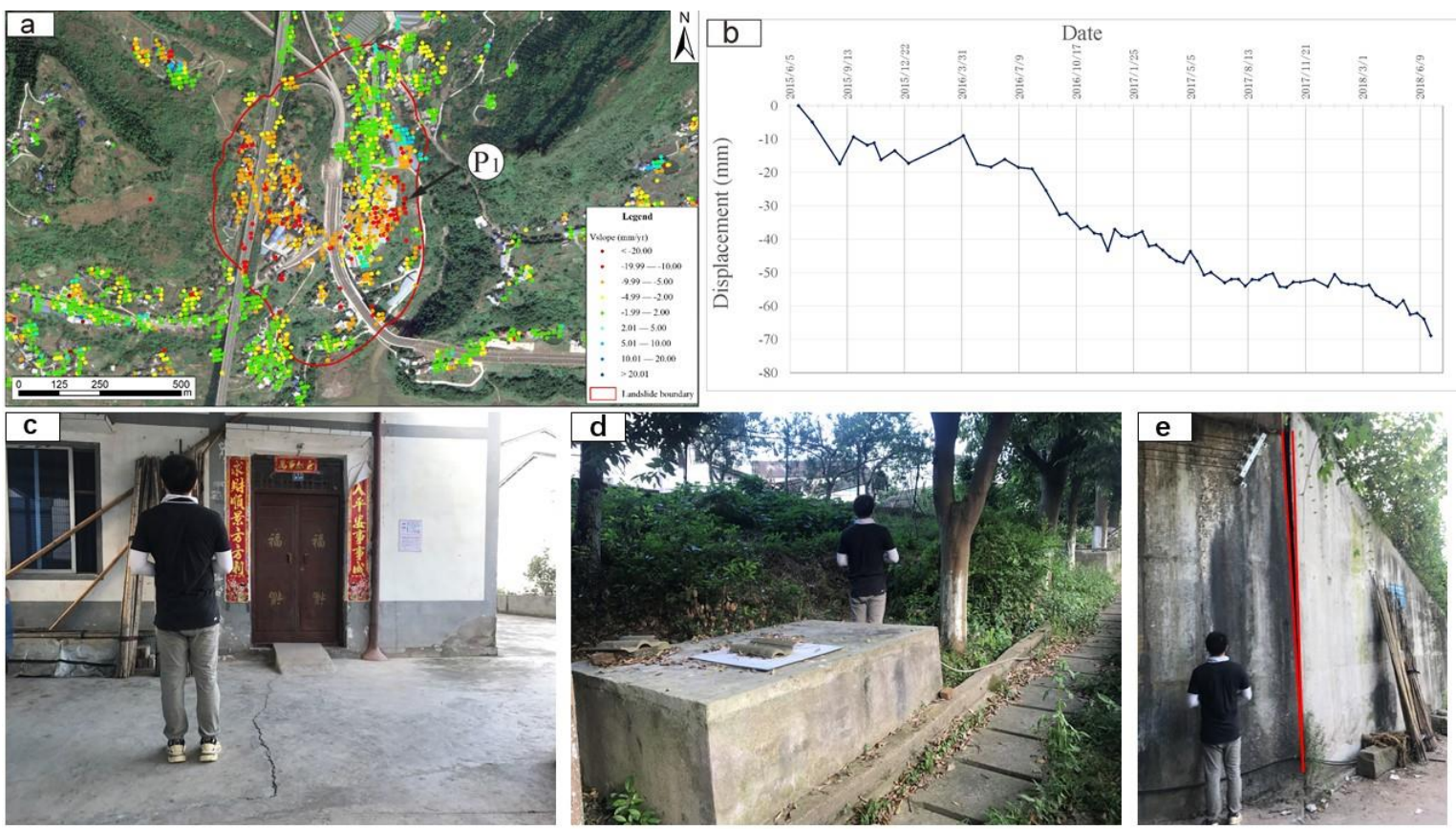

Figure 7. (a) PSInSAR deformation rate map of the Dadiping landslide. (b) InSAR time-series analysis result of persistent scatters at site P1. (c) Cracks observed at the floor of a nearby house. (d) Anti-slide piles in front of the highway. (e) Crack observed in a nearby slope protection wall.

The displacement history was greatly influenced by the periodic reservoir water level fluctuation and characterized by rapid displacements over short-term periods and a subsequent low strain rate over the long-term period. Given the joint effect of water level fluctuations and rainfall, the displacement rates showed irregular patterns that were very difficult to predict. PS spots with the highest deformations rates were found mainly at the leading edge of most of the landslides, likely owing to the rapidly changed ground coverage conditions, water level fluctuations, and the absence of permanent scatters in other sectors of the slope. In such a case, field investigation could provide more reliable information regarding the signs of deformation.

The results of the field investigation were quite similar for the other seven controlled landslides (No. 5-No.11 in Table 3). Based on the past experience in this area, although the InSAR displacement rate was steady at tens of millimeters per year, such a level of deformation would not cause much trouble for the overall stability of a controlled landslide.

\subsection{Active Controlled Landslides Areas}

Some evident deformation was detected in the Dazhou landslide, which is a landslide group consisting of five individual landslides named from Zone A to Zone E. Situated in Dazhou town, the total length of these five landslide bodies stretches over $1370 \mathrm{~m}$. Extended from south to north, Zones B, C, and D are separated by gullies and maintain their own boundaries (Figure 8). The trailing edge of them is in a gentle area on the west side of the highway, and the leading edge has a steeper slope and is permanently submerged into the Yangtze river. 

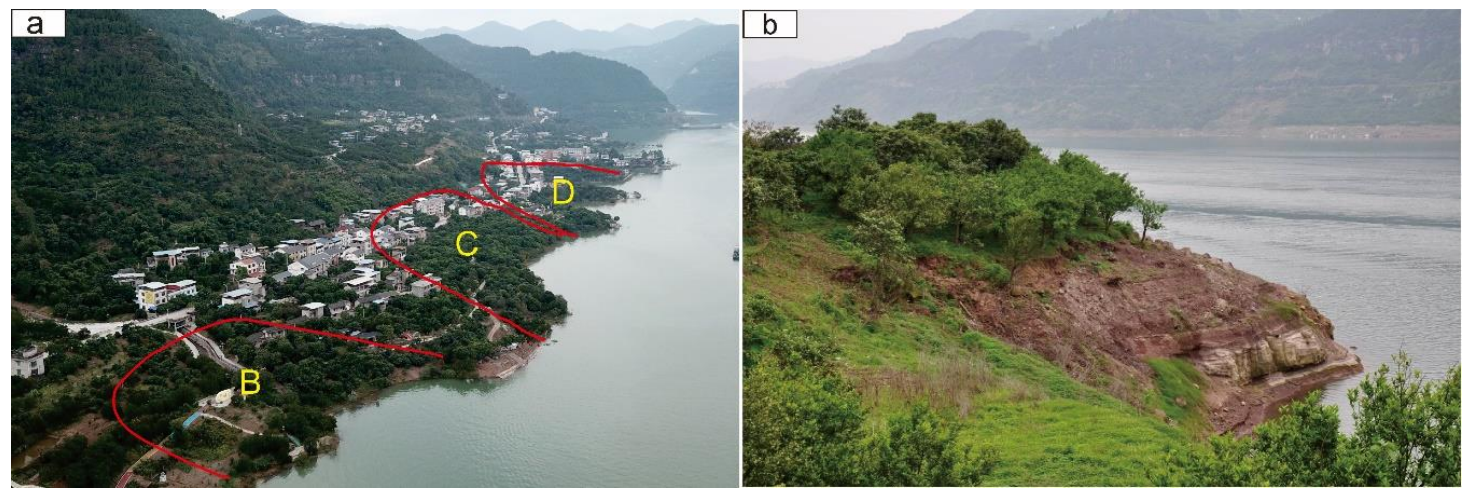

Figure 8. Photos of the Dazhou landslide: (a) Aerial photograph of the Dazhou landslide. (b) Shear crack at the front edge of the Dazhou landslide.

Previous field investigations suggested that significant deformation was found for Zones C and D, including clear signs of sliding caused by tensile rupture, such as cracks on the buildings and ground, collapse, and distortion on the road (see Figure 9). A strong deformation zone between Zones C and D is highlighted in Figure 10.
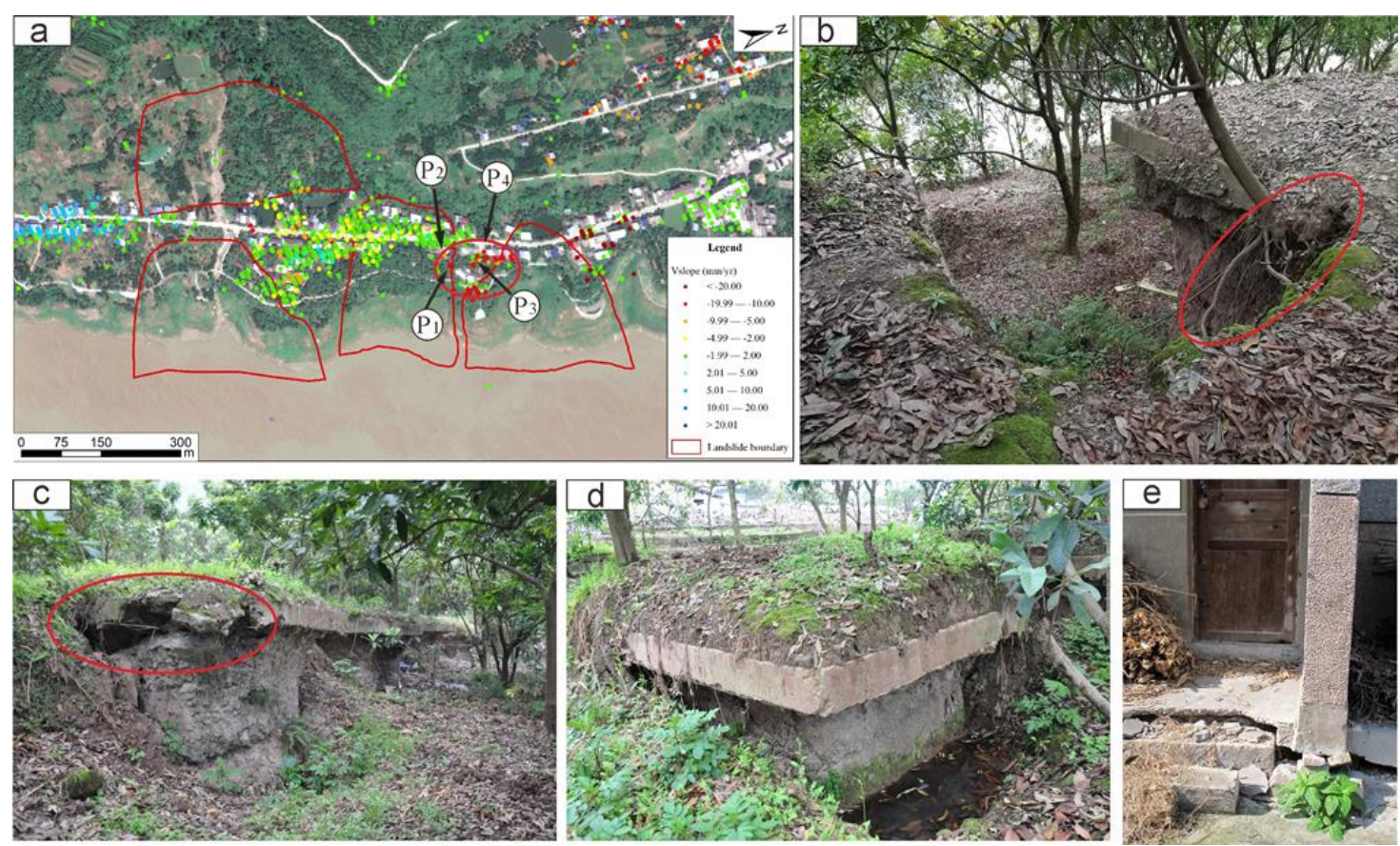

Figure 9. (a) The PSInSAR deformation rate map of the Dazhou landslide, with the strong deformation area circled in red. (b) The soil slip between the anti-slide piles observed at the circled area at site P1 (shown in a); (c) Damage to the anti-slide piles at the circled area at site P2 (shown in a). (d) An anti-slide pile shifting towards the sliding direction at site P3 (shown in a); (e). Crack observed in a nearby house at site P4 (shown in a).

The engineering remedial work for the Dazhou No.2 landslide was designed in a segmented form and the main engineering countermeasures are anti-slide piles, combined with drainage ditches and modification of the slope geometry. Based on the calculation of the slope thrust and the design load, the pile spacing was initially drawn to be $5.5-6 \mathrm{~m}$, and the pile length was $15.5 \mathrm{~m}$. In total, 29 piles were planted into the bodies of Zones B, C, and D. No obvious deformation was detected in engineering the countermeasure structures of slides $\mathrm{B}$ and $\mathrm{D}$, while some damages occurred in three anti-slide piles on the left edge of slide C (Figure 9). In total, three anti-slide piles were inclined on the left edge of slide C. 
Soil in front of the anti-slide piles moved down significantly. An evident crack, about $30 \mathrm{~cm}$ length, was observed on the second pile of the left edge of slide C. Another crack about the same length was found on the left edge of slide B. Except for the different level of soil slips in front of the piles, the pile structures were basically intact.

The information indicates that the slope is unstable at a certain depth, and the damage of engineering project could influence the overall stability of slide $C$; to assess the exact deformation of the underground pile section and the depth of the sliding surface subsurface data are needed.

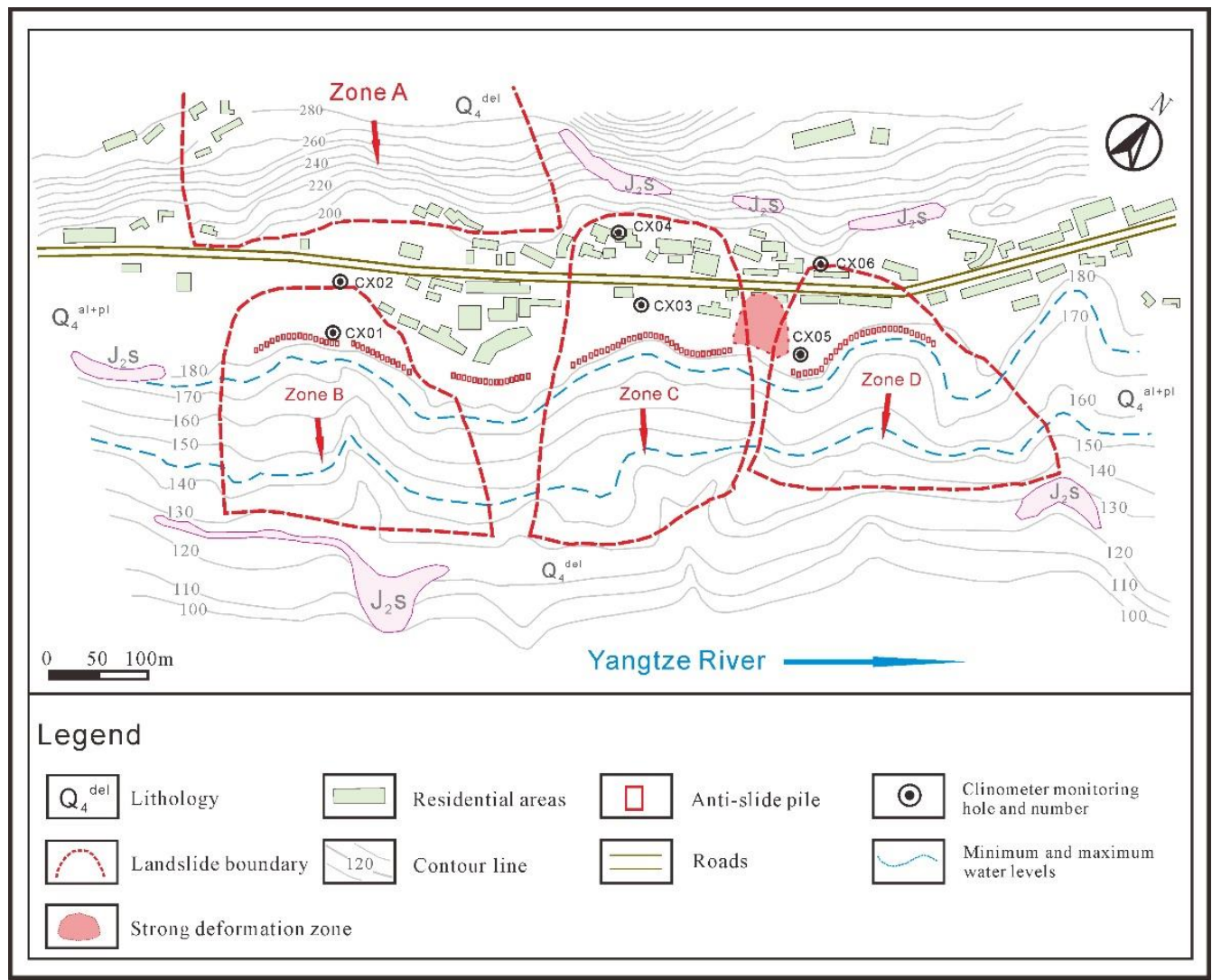

Figure 10. The layout map of the Dazhou landslide showing the distribution of the anti-slide piles.

As the Dazhou landslide is one of the few controlled landslides that was still carefully monitored, more sources of monitoring data could be introduced to verify its deformation. The positions of the monitoring devices are shown in Figure 10; all of the monitoring points were arranged along the three cross sections of Zones B, C, and D. The position of the piles was also depicted in Figure 10. The most significant deformation occurred between Zones $C$ and $D$, where no piles were designed to protect this area. This deformation could also be verified with InSAR surface monitoring: PSs with relatively high deformation rates were located exactly at the same place between Zone $\mathrm{C}$ and $\mathrm{D}$.

Figure 11 shows the inclinometer data of the Dazhou landslide, showing that a significant movement was detected in 2017. The sharp change in the curve profile reveals the depth of the sliding surface, which was also consistent with the result of the drilling exploration. The inclinometer data shows that the creep deformation of the Dazhou landslide continued along the slip surface and some of the data missing from March 2017 to December 2017 was due to the instrument damage, when the semi-automatic inclinometer became stuck in the borehole, which also indicated a relatively large deformation of the landslide body. CX06, an inclination hole located at the trailing edge of Zone D, showed that the slip surface exists at approximately $16 \mathrm{~m}$ depth while the surface movement was not evident during the monitoring period. The inclinometer data also revealed a different degree of 
deformation that Dazhou landslide Zone D is developing, and this local deforming circumstance was likely caused by the segmented anti-slide piles.

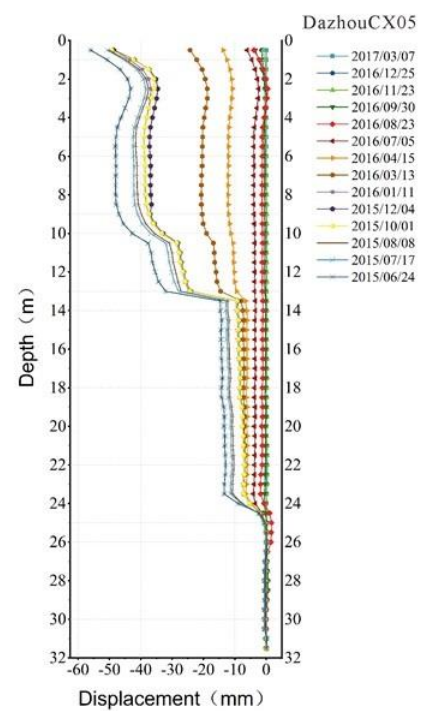

(a)
Date

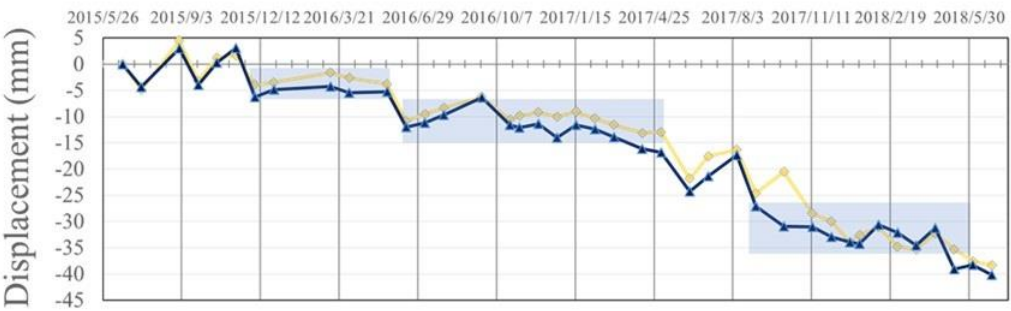

(b)

Figure 11. Monitoring data of the Dazhou landslide: (a) Borehole inclinometer data related to the time span June 2015-May 2018. (b) The PSInSAR deformation rate map of the Dazhou landslide, with the strong deformation area circled in red.

The outcomes of the regional scale and local scale analyses support the conclusion that the rapid fluctuation of the reservoir water level may have induced localized sliding activity in some sectors of the main body of the Dazhou landslide. Even if we have no reason to claim that the design of the engineering countermeasures of the Dazhou landslides were invalid, the evolution process of the Dazhou landslide could have been greatly influenced by the piles planted in the landslide body. For instance, the original separated boundaries of Zone $C$ and $D$ are now connected by a strong deforming zone, which was generated after the implementation of the anti-slide piles.

Another case is the Kangjiapo landslide. During a routine inspection on the second Wanzhou Yangtze River Bridge, on 12 July 2018, we noticed that a brick at the edge of the No.6 pier was sunk more than $60 \mathrm{~mm}$. A T-shape beam of the north shore approach bridge was noticed to be displaced toward the bank. According to the on-site field investigation, the pier No.6 was suspected to be shifting towards the river center, posing a serious threat to the bridge structure and vehicle safety.

A series of PSs with a high moving rate were captured at the front edge of the nearby Kangjiapo landslide, which was a controlled landslide, and the highest slope displacement rate reached $17.88 \mathrm{~mm} / \mathrm{y}$ (Figure 12). Since the engineering remedial work of Kangjiapo landslide were established in 2003 and, at present, the surface of the landslide area is covered by a large number of buildings, many treatment projects cannot be directly observed. Therefore, the deformation degree of the engineering measures was impossible to assess. However, since noticeable deformation happened at the bridge and nearby landslide, some actions were taken immediately to alleviate this danger, such as landslide temporary reinforcement with mini-scale anti-slide piles. While the landslide body was submerged within the range of the reservoir water fluctuating area, further reinforcement to both landslides and bridge piers were extremely difficult to implement. 

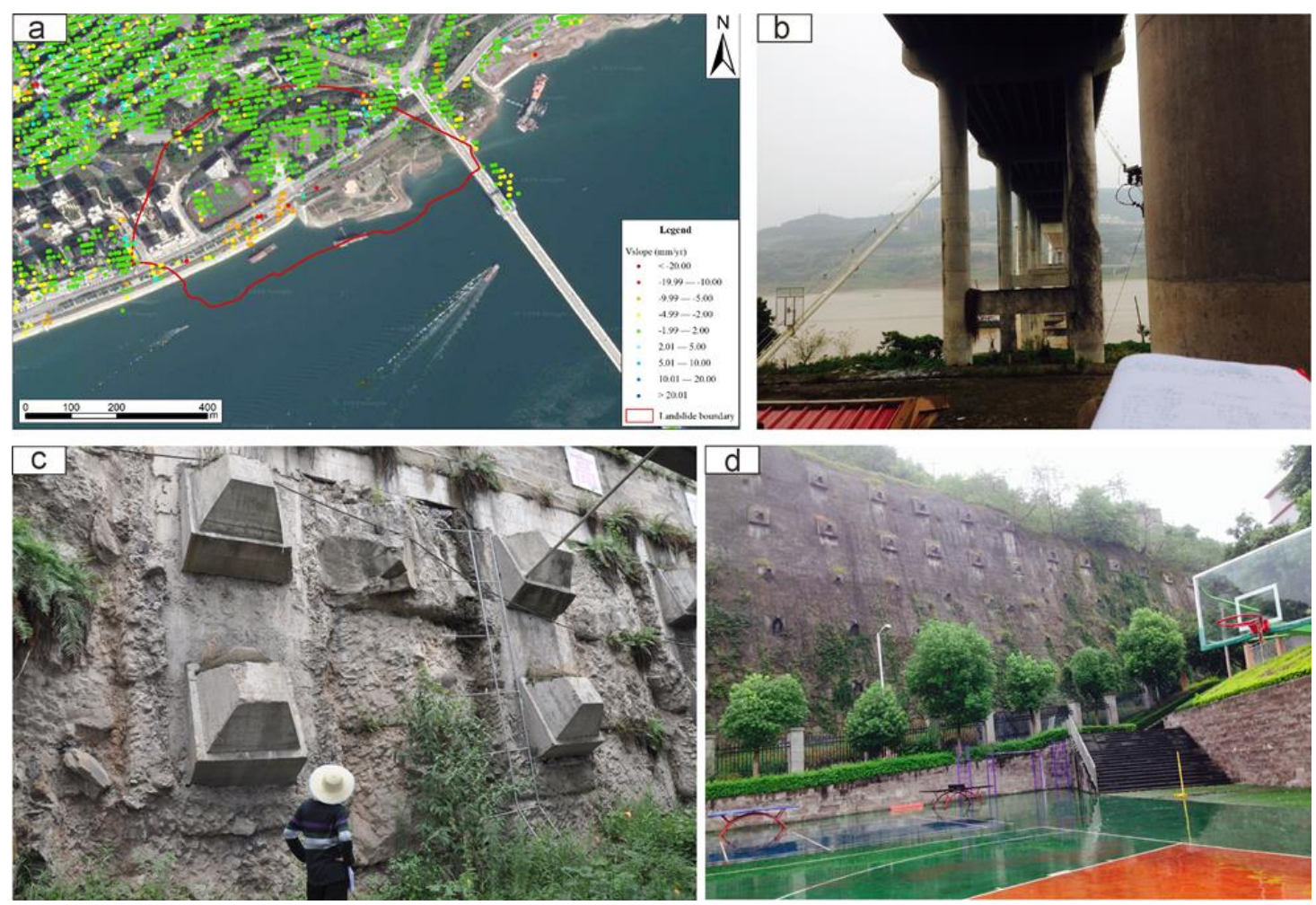

Figure 12. (a) PSInSAR deformation rate map of the Kangjiapo landslide. (b) Pier sinking observed at the middle part of the landslide body. (c) Anchors at the trailing edge of the Kangjiapo landslide.

(d) Anchors at the landslide middle part of the landslide.

\section{Discussion}

Evaluating the effect of landslide engineering remedial works at the regional scale is a relatively unattempted task and, even at the slope scale, is usually time-consuming and highly empirical: For instance, researchers attempted to build an evaluating system considering factors from different aspects employing an integrated fuzzy hierarchy process theory [24].

The main purpose of this study is to propose a multi-scale integrated monitoring method to prevent landslide remedial works from invalidation. It is true that a remedial work's effectiveness may be considered inappropriate or seriously damaged only with very large deformations; however, a monitoring program, like the one proposed, may identify precursor signs that could allow for intervention before reaching critical conditions.

The presented methodology is low-cost, easy to perform, and very straightforward to communicate to citizens and authorities. According to the requirements of the local government administration, casualties, and property losses caused directly by geohazards in the TGRA should be completely eradicated, and, consequently, large investments on scientific research and on hazard mitigation have been undertaken. Our study proves that, up to now, great accomplishments have been achieved: Overall, the engineering remedial works in the Wanzhou to Yunyang reservoir section played a significant role in the landslide control as most of the controlled landslides remained inactive, and most of the active landslides were not controlled with engineering remedial work.

The majority of the controlled landslides are no longer being carefully monitored, as typically the designs of controlling projects are relatively safe and hiring other forms of monitoring equipment is considered as an avoidable investment. Thus, it is hard to obtain other sources of monitoring data to observe the difference of deformation rates before and after the remedial works $[35,36]$. In such condition, the joint use of InSAR data and field investigation became the most direct and reliable mean to detect possible criticalities and to study the evolution process of controlled landslides $[19,20]$. The results of our application also showed that remote sensing technologies alone were not sufficient to 
obtain complete and reliable information. For example, as we reported in the results section, owing to the relatively short interaction time between the engineering remedial work and the sliding body, it is difficult to determine whether the landslide remedial work is valid or not in the Dadiping landslide. Thus, further attention should be paid over the next few years, and periodic field investigation or even ground monitoring instrument are highly recommended; besides, although a series of active PS spots were observed at the Kangjiapo landslide, the reported deformation of the bridge pier was still hard to capture. InSAR can detect deformation related to the interaction between the ground and infrastructures; however, it is not suitable to measure internal deformation of the structure itself.

Although the general trend of the deformation is captured by the InSAR time-series analysis, the detailed and short-term displacements are not always completely in accordance with the GPS data. This is likely due to the inconsistency between the projection direction of the InSAR displacement results and the GPS data, and the lowest spatial and temporal resolution of the accessible SAR images; however, this drawback did not prevent us from recognizing a potential instability hotspot in the framework of a regional scale investigation. Further and more thorough analyses are then needed in the highlighted hotspots with other methods: in this perspective, the ground monitoring has an unsubstituted advantage over InSAR in real-time monitoring and the two techniques can be considered complimentary.

The proposed integrated monitoring method provided a solution for such circumstances and proved that the InSAR regional-scale deformation mapping must be completed by regular field investigations or ground monitoring in order to avoid missing deformations that may be of serious consequence. With Sentinel satellite InSAR, the deformative scenario at a wide scale could be updated periodically, for instance every year or less, and the necessity of extensive field investigation could be largely reduced, at least for some typologies of landslides.

The majority of the engineering remedial work in the TGRA started construction after the establishment of the Three Gorges Dam in 2003, and was sequentially built up later. Since the huge scale of landslides engineering remedial work was extremely costly due to the unexpectedly large number of natural hazards, the hazard engineering remedial works were implemented in a multi-stage plan to alleviate the financial pressure on the government. Along with this staged plan came a new problem regarding the changing setting of prevention work design. The remedial work design engineer could have not known the presence of such intense urban growth and environment changes; thus, the additional weight and interference may cause the remedial work invalidation and the landslide reactivation. For example, several landslides are distributed at the north bank of the second Wanzhou Yangtze River Bridge, including landslides with already implemented engineering remedial work or ancient landslides in a dormant state. However, the heavy load from the bridge and buildings could have largely fostered the landslide reactivation, which may have led to the sinking of the bridge piers. In such case, the landslide deformation may not be attributed to the invalidation of its engineering remedial work, but mainly due to the changes in the surrounding environmental conditions. Landslides reactivations resulting from land use changes (and particularly from urban growth) might become a general issue in this region, and thus monitoring programs are urgently needed [37]. The setting changed due to anthropic (e.g., urban expansion) and natural (e.g., climate change) factors, thus the long-term effectiveness of remedial measures should be constantly checked.

The geohazard prevention and control plan of the TGRA was formulated based on the idea of hazard risk management. The engineering remedial works were primarily built on landslides with many anthropic elements (mainly buildings and roads) exposed at risk. This circumstance is ideal for the application of our methodology because the urban environment provides reflectors for and effective InSAR deformation analysis at the regional scale, and, in addition, it is possible to observe deformation features, such as cracks and other building damage, directly through field investigation. 


\section{Conclusions}

This study provided a practical example in verifying the effectiveness of landslide engineering remedial works and the geomorphological stability characterization of landslides employing an InSAR and conventional ground monitoring combined method. To this aim, the effectiveness of InSAR-based techniques was exploited at the regional scale to determine possible hot spots of landslide hazards. The matching with landslide inventories allowed us to downscale the analysis to the slope scale where possible precursory signals of instability were identified. At this scale, where deemed necessary, more detailed analyses were conducted: Field surveys and conventional ground monitoring data had the irreplaceable advantages in obtaining substantial insights for each hotspot, including deformation mechanisms and the inducing factors.

The results correspond to the field evidence and matched with the outcomes of previous research in this area. Compared to previous studies, the effect of geohazard engineering remedial works was emphasized and taken as a primary consideration. The multi scale analysis allowed us to detect precursory signals of possible instability in certain sections of the controlled landslides. In general, with a total of 310 mapped landslides, 52 of them (13.87\%) were classified as active in a slow-moving state. A total of 58 landslides were instrumented (18.71\%), and others were slowed through remedial efforts. We found two controlled landslides that were confirmed to be active, while another nine cases were suspected to be active and demand further attention.

Currently, extensive protective measures have been planned and carried out; however, it is not feasible to avoid all threats or protect all affected areas. Considering that we cannot prevent all landslides and landslide remedial work could have been weakened or even failed, different strategies involving monitoring and early-warning systems are valid options for risk mitigation. This strategy relies on satellite InSAR, starting from the most urgent situations, combining advanced techniques with practical experience. This could not only greatly reduce the effort of field work but also effectively identify potentially dangerous landslides. The proposed procedure is low-cost, easy to perform and very straightforward to communicate to citizens and authorities. It could be easily implemented on very wide areas to assess the slope stability and to investigate the effectiveness of large-scale governmental risk mitigation programs, identifying precursor signals that could allow for intervention before reaching critical conditions.

Author Contributions: Conceptualization, S.L.; methodology, S.L.; investigation, S.L., C.Z., and Y.Z.; data curation, S.L. and Y.Z.; writing-original draft preparation, S.L. and S.S.; writing-review and editing, S.S., F.R., C.Z., and K.Y.; supervision, K.Y. and N.C.; funding acquisition, K.Y. All authors have read and agreed to the published version of the manuscript.

Funding: This research was funded by the National Key R\&D Program of China (No.292 2018YFC0809400).

Acknowledgments: We greatly appreciate the support from Jiang $\mathrm{Wu}$ and Qingli Liu for providing data and material. We also thank the editor and anonymous referees for their comments and contributions.

Conflicts of Interest: The authors declare no conflict of interest.

\section{References}

1. Froude, M.J.; Petley, D.N. Global fatal landslide occurrence from 2004 to 2016. Nat. Hazards Earth Syst. Sci. 2018. [CrossRef]

2. Fourniadis, I.G.; Liu, J.G.; Mason, P.J. Regional assessment of landslide impact in the Three Gorges area, China, using ASTER data: Wushan-Zigui. Landslides 2007, 4, 267-278. [CrossRef]

3. Tantianuparp, P.; Shi, X.; Zhang, L.; Balz, T.; Liao, M. Characterization of landslide deformations in Three Gorges area using multiple InSAR data stacks. Remote Sens. 2013, 5, 2704-2719. [CrossRef]

4. Yin, Y.; Huang, B.; Wang, W.; Wei, Y.; Ma, X.; Ma, F.; Zhao, C. Reservoir-induced landslides and risk control in Three Gorges Project on Yangtze River, China. J. Rock Mech. Geotech. Eng. 2016, 8, 577-595. [CrossRef]

5. Li, S.; Xu, Q.; Tang, M.; Iqbal, J.; Liu, J.; Zhu, X.; Liu, F.; Zhu, D. Characterizing the spatial distribution and fundamental controls of landslides in the three gorges reservoir area, China. Bull. Eng. Geol. Environ. 2018, 78, 4275-4290. [CrossRef] 
6. Huang, D.; Gu, D.M. Influence of filling-drawdown cycles of the Three Gorges reservoir on deformation and failure behaviors of anaclinal rock slopes in the Wu Gorge. Geomorphology 2017, 295, 489-506. [CrossRef]

7. Yin, K.; Chen, L.; Ma, F.; Cheng, W. Practice and thinking of landslides risk management considering secondary consequences in the Three-Gorges Reservoir, China. In Landslides and Engineered Slopes. Experience, Theory and Practice; CRC Press: London, UK, 2019; pp. 2097-2105.

8. Tang, H.; Wasowski, J.; Juang, C.H. Geohazards in the Three Gorges reservoir area, China-Lessons learned from decades of research. Eng. Geol. 2019, 261, 105267. [CrossRef]

9. Bardi, F.; Raspini, F.; Frodella, W.; Lombardi, L.; Nocentini, M.; Gigli, G.; Morelli, S.; Corsini, A.; Casagli, N. Monitoring the rapid-moving reactivation of earth flows by means of GB-InSAR: The April 2013 Capriglio Landslide (Northern Appennines, Italy). Remote Sens. 2017, 9, 165. [CrossRef]

10. Raspini, F.; Bardi, F.; Bianchini, S.; Ciampalini, A.; Del Ventisette, C.; Farina, P.; Ferrigno, F.; Solari, L.; Casagli, N. The contribution of satellite SAR-derived displacement measurements in landslide risk management practices. Nat. Hazards 2017. [CrossRef]

11. Jaboyedoff, M.; Oppikofer, T.; Abellán, A.; Derron, M.H.; Loye, A.; Metzger, R.; Pedrazzini, A. Use of LIDAR in landslide investigations: A review. Nat. Hazards 2012. [CrossRef]

12. Bardi, F.; Frodella, W.; Ciampalini, A.; Bianchini, S.; Del Ventisette, C.; Gigli, G.; Fanti, R.; Moretti, S.; Basile, G.; Casagli, N. Integration between ground based and satellite SAR data in landslide mapping: The San Fratello case study. Geomorphology 2014. [CrossRef]

13. Crosetto, M.; Monserrat, O.; Cuevas-González, M.; Devanthéry, N.; Crippa, B. Persistent scatterer interferometry: A review. ISPRS J. Photogramm. Remote Sens. 2016, 115, 78-89. [CrossRef]

14. Cascini, L.; Fornaro, G.; Peduto, D. Advanced low- and full-resolution DInSAR map generation for slow-moving landslide analysis at different scales. Eng. Geol. 2010, 112, 29-42. [CrossRef]

15. Baer, G.; Magen, Y.; Nof, R.N.; Raz, E.; Lyakhovsky, V.; Shalev, E. InSAR measurements and viscoelastic modeling of sinkhole precursory subsidence: Implications for sinkhole formation, early warning, and sediment properties. J. Geophys. Res. Earth Surf. 2018, 123, 678-693. [CrossRef]

16. Raspini, F.; Bianchini, S.; Ciampalini, A.; Del Soldato, M.; Montalti, R.; Solari, L.; Tofani, V.; Casagli, N. Persistent scatterers continuous streaming for landslide monitoring and mapping: The case of the Tuscany region (Italy). Landslides 2019, 16, 2033-2044. [CrossRef]

17. Carlà, T.; Intrieri, E.; Raspini, F.; Bardi, F.; Farina, P.; Ferretti, A.; Colombo, D.; Novali, F.; Casagli, N. Perspectives on the prediction of catastrophic slope failures from satellite InSAR. Sci. Rep. 2019, 9, 1-9. [CrossRef]

18. Berardino, P.; Costantini, M.; Franceschetti, G.; Iodice, A.; Pietranera, L.; Rizzo, V. Use of differential SAR interferometry in monitoring and modelling large slope instability at Maratea (Basilicata, Italy). Eng. Geol. 2003. [CrossRef]

19. Di Maio, C.; Fornaro, G.; Gioia, D.; Reale, D.; Schiattarella, M.; Vassallo, R. In situ and satellite long-term monitoring of the Latronico landslide, Italy: Displacement evolution, damage to buildings, and effectiveness of remedial works. Eng. Geol. 2018. [CrossRef]

20. Confuorto, P.; Di Martire, D.; Infante, D.; Novellino, A.; Papa, R.; Calcaterra, D.; Ramondini, M. Monitoring of remedial works performance on landslide-affected areas through ground- and satellite-based techniques. Catena 2019, 178, 77-89. [CrossRef]

21. Xia, Y.; Kaufmann, H.; Guo, X. Differential SAR interferometry using corner refletors. In Proceedings of the IEEE International Geoscience and Remote Sensing Symposium (IGARSS), Toronto, ON, Canada, 24-28 June 2002. [CrossRef]

22. Shi, X.; Liao, M.; Li, M.; Zhang, L.; Cunningham, C. Wide-area landslide deformation mapping with multi-path ALOS PALSAR data stacks: A case study of Three Gorges area, China. Remote Sens. 2016, 8, 136. [CrossRef]

23. Shi, X.; Zhang, L.; Zhou, C.; Li, M.; Liao, M. Retrieval of time series three-dimensional landslide surface displacements from multi-angular SAR observations. Landslides 2018. [CrossRef]

24. Zhang, Y.; Shi, S.; Song, J.; Cheng, Y. Open image in new windowEvaluation on Effect for the Prevention and Control Against the Landslide Disasters in the Three Gorges Reservoir Area. In Landslide Science for a Safer Geoenvironment; Sassa, K., Canuti, P., Yin, Y., Eds.; Springer: Cham, Switzerland, 2014. [CrossRef]

25. Yang, B.; Yin, K.; Xiao, T.; Chen, L.; Du, J. Annual variation of landslide stability under the effect of water level fluctuation and rainfall in the Three Gorges reservoir, China. Environ. Earth Sci. 2017, 76, 1-17. [CrossRef] 
26. Xiao, T.; Segoni, S.; Chen, L.; Yin, K.; Casagli, N. A step beyond landslide susceptibility maps: A simple method to investigate and explain the different outcomes obtained by different approaches. Landslides 2019. [CrossRef]

27. Gui, L. Research on Landslide Development Regularities and Risk in Wan Zhou District, Three Gorges Reservoir. Ph.D. Thesis, China University of Geosciences, Wuhan, China, 2014.

28. Miao, H.; Wang, G.; Yin, K.; Kamai, T.; Li, Y. Mechanism of the slow-moving landslides in jurassic red-strata in the three gorges reservoir, China. Eng. Geol. 2014. [CrossRef]

29. Tofani, V.; Raspini, F.; Catani, F.; Casagli, N. Persistent Scatterer Interferometry (PSI) technique for landslide characterization and monitoring. Remote Sens. 2013, 5, 1045-1065. [CrossRef]

30. Ferretti, A.; Prati, C.; Rocca, F. Nonlinear subsidence rate estimation using permanent scatterers in differential SAR interferometry. IEEE Trans. Geosci. Remote Sens. 2000, 38, 2202-2212. [CrossRef]

31. Ferretti, A.; Prati, C.; Rocca, F. Permanent scatterers in SAR interferometry. IEEE Trans. Geosci. Remote Sens. 2001, 39, 8-20. [CrossRef]

32. Lu, P.; Catani, F.; Tofani, V.; Casagli, N. Quantitative hazard and risk assessment for slow-moving landslides from Persistent Scatterer Interferometry. Landslides 2013, 11, 685-696. [CrossRef]

33. Getis, A.; Ord, J.K. The analysis of spatial association by use of distance statistics. Geogr. Anal. 1992. [CrossRef]

34. Popescu, M.E.; Sasahara, K. Engineering measures for landslide disaster mitigation. In Landslides—Disaster Risk Reduction; Springer: Berlin/Heidelberg, Germany, 2009. [CrossRef]

35. Hu, X.; Tan, F.; Tang, H.; Zhang, G.; Su, A.; Xu, C.; Zhang, Y.; Xiong, C. In-situ monitoring platform and preliminary analysis of monitoring data of Majiagou landslide with stabilizing piles. Eng. Geol. 2017, 228, 323-336. [CrossRef]

36. Zhang, Y.; Hu, X.; Tannant, D.D.; Zhang, G.; Tan, F. Field monitoring and deformation characteristics of a landslide with piles in the Three Gorges reservoir area. Landslides 2018, 15, 581-592. [CrossRef]

37. Notti, D.; Galve, J.P.; Mateos, R.M.; Monserrat, O.; Lamas, F.; Chacón, F.F.; Roldán-García, F.J.; Pérez-Peña, J.V.; Crosetto, M.; Azañón, J.M. Human-induced coastal landslide reactivation. Monitoring by PSInSAR techniques and urban damage survey (SE Spain). Landslides 2015, 12, 1007-1014. [CrossRef]

(C) 2020 by the authors. Licensee MDPI, Basel, Switzerland. This article is an open access article distributed under the terms and conditions of the Creative Commons Attribution (CC BY) license (http://creativecommons.org/licenses/by/4.0/). 